Http://lingua.pusatbahasa.or.id; Email: presslingua@gmail.com

Center of Language and Culture Studies, Surakarta, Indonesia

Anggororeni, Pramesty; Santosa, Riyadi \& Wiratno, Tri. 2018. Analisis Terjemahan Makna Interpersonal dalam Dubbing Film Thomas and Friend: Blue Mountain Mistery. Lingua (2018), 15(1): 7 18. DOI: 10.30957/lingua.v15i.426.

\title{
ANALISIS TERJEMAHAN MAKNA INTERPERSONAL DALAM DUBBING FILM THOMAS AND FRIENDS: BLUE MOUNTAIN MYSTERY
}

\section{Pramesty Anggororeni, Riyadi Santosa \& Tri Wiratno Universitas Sebelas Maret Jl. Ir. Sutami 36A Kentingan, Surakarta Email: pramestyanggororeni@yahoo.com}

\begin{abstract}
This reasearch aims to describe translation qualities of proposal clause, explain the effect of translation techniques to the translation qualities and the impact of proposal translations to the children as target viewer on dubbing interpersonal-transacsional: proposal "Thomas and Friends: Blue Mountain Mystery" the movie. This descriptive-qualitative research applies purposive sampling techniques. The main resource is dubbing "Thomas and Friends: Blue Mountain Mystery" the movie and its indonesian version. Data were collected using: (1) document analysis to obtain the clause of interpersonal-transacsional: proposal, (2) questionnaire and interview to obtain translation quality data which covers accuracy, acceptability and readability. The result of the study shows that movie dubbing used narrative genre and its text structure is devided into orientation, complication and resolution. Each structure consists of declarative clause, interogative and imperative. The translation shifts occured in the forms of declarative clause and imperative clause. The shift types are in the clause type, proposal meaning or social function, and in both clause type and meaning.
\end{abstract}

Key Word: clause, proposal, translation techniques, translation quality, Systemic Functional Linguistics.

\section{DOI: 10.30957/lingua.v15i1.426.}

\section{PENDAhULUAN}

Perkembangan film saat ini semakin cepat dan universal, baik di dalam maupun luar negeri, meliputi berbagai genre dengan kualitas hasil produksi tinggi yang memperhatikan kelayakan konsumsi bagi masyarakat. Di Indonesia, film domestik dapat langsung dinikmati oleh para penonton tanpa adanya kendala bahasa. Namun, film asing yang masuk ke Indonesia langsung dinikmati oleh seluruh kalangan masyarakat karena kendala yang muncul akibat perbedaan bahasa. Kendala bahasa sangat berpengaruh terhadap kualitas pesan atau nilai moral yang ingin disampaikan film tersebut kepada para penontonnya. Apabila dibiarkan, masalah ini mengakibatkan ketidakmaksimalan manfaat suatu film dalam menyampaikan nilai atau pesan moral dan nilai budaya yang dimaksudkan oleh penulis cerita film tersebut. Tampak sekali bahwa bahasa begitu berpengaruh terhadap kemanfaatan suatu kreativitas dan pendidikan. 
Sebagai upaya memecahkan permasalahan bahasa, penerjemahan pun muncul sebagai sarana penyambung lidah pihak sumber kepada pihak sasaran. Penerjemahan film dapat berupa teks atau disebut subtitling dan juga dapat berbentuk dubbing. Keduanya tergolong dalam audio-visual translation (AVT). Disamping itu terdapat pula penerjemahan film dalam bentuk dubbing namun juga tersedia subtitle-nya. Masingmasing bentuk memiliki kriteria sendiri dalam penggunaannya bersama film sumbernya (teks BSu). Dalam dubbing, penonton tidak perlu membaca karena terjemahannya sudah tersaji langsung dalam tuturan tokoh film. Dengan demikian, penonton seakanakan menikmati film domestik. Penonton tiqak hanya dapat menikmati terjemahannya secara monoton, namun juga perasaan tokoh dapat terungkap secara padu melalui gestur, intonasi, dan bahasa. Perpaduan ini secara harmoni membentuk suatu seni tersendiri karena sebuah film akan semakin mudah dipahami oleh penontonnya. Nilai moral, budaya dan pesan yang ingin disampaikan pun teralihkan secara maksimal dan diserap oleh penontonnya dengan lebih maksimal pula.

Anak-anak sebagai target penonton, dengan usia 7-11 tahun, tentunya akan lebih memahami suatu film yang disajikan dalam bahasa yang mereka pahami. Mengingat, anak berada dalam tahap belajar berbahasa. Pada usia tersebut kemampuan membaca pun masih terbatas. Namun, anak juga membutuhkan bimbingan moral yang tersaji dalam bentuk audio visual. Film dengan dubbing tentu akan sangat membantu dalam pembentukan karakter anak. Nurgiyantoro (2005) mengungkapkan, anak pada usia 7-11 tahun berada pada tahap operasional konkret. Pada tahap ini anak mulai dapat memahami logika secara stabil. Mereka pun mulai mengenal karakter dan mengembangkan imajinasi. Selain itu, pada tahap ini pula mereka mulai mampu memprediksi kelanjutan cerita, dengan demikian dapat disimpulkan bahwa anak-anak pada tahap operasional konkret mulai mampu memikirkan dan memecahkan masalah yang dihadapi terutama yang terjadi pada tokoh protagonis. Berdasarkan alasan-alasan inilah, dubbing menjadi salah satu cara untuk menyampaikan pesan yang positif bagi anak dan sarana belajar, baik belajar bahasa maupun belajar membentuk karakter. Semakin tersampaikan dengan baik nilai-nilai yang terkandung dalam film maka menunjukkan semakin tinggi pula kualitas terjemahannya. Tentu hal ini dipengaruhi juga oleh perpaduan yang signifikan dan selaras antara bahasa lisan, bahasa tubuh tokoh, dan intonasi yang dimainkan oleh seorang dubber.

Penelitian tentang dubbing sering kali belum spesifik, masih merujuk pada kajian dubbing secara umum. Penelitian sebelumnya juga lebih banyak menggunakan film atau pun acara untuk level usia dewasa sebagai objek penelitiannya. Film yang digunakan dalam penelitian ini adalah Thomas and Friends: Blue Mountain Mystery yang merupakan salah satu film seri anak yang sangat digemari bahkan tokoh-tokoh di dalamnya pun menjadi idola bagi anak-anak. Tokoh-tokoh dalam film Thomas mencontohkan karakter-karakter yang dapat dijadikan bahan pembelajaran bagi penonton target. Pada dubbing film tersebut, peneliti menemukan klausa yang bermakna interpersonal-transaksional: proposal dilihat dari sudut pandang Linguistik Sistemik Fungsional. Pada klausa-klausa tersebut juga terdapat pergeseran jenis klausa 
antara BSu ke BSa atau pergeseran fungsi sosial. Contoh penemuan peneliti ditunjukkan pada tabel 1 berikut.

Tabel 1. Contoh pergeseran jenis klausa bermakna interpersonal-transaksional: proposal

Konteks Situasi:

03:35

Di suatu hari yang sibuk, di tambang Gunung Biru, Para kereta kecil sedang bekerja mengangkut tambang batu tulis. Tiba-tiba batu penutup jembatan Blondin lepas yang mengakibatkan jembatan Blondin runtuh. Reruntuhan jembatan mengenai sebuah kereta diesel, Paxton. Hal itu menyebabkan Paxton mengalami kerusakan dan harus segera diperbaiki.

\begin{tabular}{|c|c|}
\hline BSu (Dubbing Bahasa Inggris) & $\begin{array}{l}\text { BSa (Dubbing Bahasa } \\
\text { Indonesia) }\end{array}$ \\
\hline $\begin{array}{l}\text { Paxton: I wonder if someone could help } \\
\text { me. }\end{array}$ & $\begin{array}{l}\text { Paxton: Ada yang bisa } \\
\text { membantuku? }\end{array}$ \\
\hline Proposal & Proposal \\
\hline Deklaratif & Interrogatif \\
\hline
\end{tabular}

Dari data pada Tabel 1 maka peneliti tertarik pada klausa dengan makna proposal pada film Thomas and Friends: Blue Mountain Mystery untuk diteliti lebih lanjut berkenaan dengan kualitas terjemahannya, teknik penerjemahan dan dampak teknik tersebut bagi pemahaman penonton. Selain itu, peneliti tertarik untuk mengkaji terjemahan dengan mempertimbangkan struktur teksnya. Penelitian terdahulu yang mengkaji makna interpersonal masih belum spesifik dalam pembatasan data. (McCabe \& Heilman, 2007; Pengsun \& Fengfeng, 2013). Kedua penelitian tersebut telah menggunakan sistem modalitas, bahkan McCabe \& Heilman (2007) menggunakan Appraisal dan mengambil data klausa yang bermakna proposisi. Namun, penelitiannya juga menganalisis makna tekstual. Peneliti-peneliti yang mengkaji makna interpersonal tersebut menggunakan objek penelitian yang fokus pada tema dewasa. Pengsun \& Fengfeng (2013) mengkaji makna interpersonal dalam pidato pemilihan presiden. Lain halnya dengan McCabe \& Heilman (2007), mereka mengambil objek bidang jurnalistik yaitu laporan berita dan editorial. Penelitian-penelitian tersebut belum ada yang menggunakan film sebagai objek penelitian. Hal ini menjadi celah bagi peneliti untuk mengkaji film dengan memfokuskan masalah pada makna interpersonal.

Penelitian sebelumnya sering kali masih mengaitkan dubbing dengan subtitling dengan cara membandingkan keduannya, namun apa yang dibahas masih terlalu umum. (Szarkowska, 2005; Pettit, 2005; Tveist, 2009; Weibel dan Groner, 2009; Jankowska,2010). Walaupun Pettit (2005) telah fokus pada bahasa sehari-hari, bahasa standar, dan bahasa formal, penelitian tersebut masih mengkaji beberapa topik penelitian dan belum spesifik. Film anak memang pernah dikaji, namun bukan jenis film seri. (Jankowska, 2010; Burczynska, 2012). Keduanya fokus pada elemen-elemen humor dan cultural item. Namun, elemen humor dan cultural item telah sering diteliti. 
Pergeseran dalam dubbing pun telah dikaji dalam Blinn (2008) dan Sitoresmi (2012). Kedua penelitian tersebut fokus menggunakan analisis teknik penerjemahan, belum mengkaji menurut fungsi sosial suatu teks atau pendekatan grammar.

Dengan demikian, ada celah bagi peneliti untuk menggunakan pendekatan grammar. Berdasarkan review tersebut, peneliti mempunyai kesempatan yang berkaitan dengan dubbing, karena masih sedikit penelitian yang fokus untuk mengkaji dubbing secara spesifik, terutama dengan bahasa Indonesia sebagai BSa dan masyarakat Indonesia sebagai target viewer. Para peneliti pun masih meninggalkan masalah yang dapat diteliti lebih lanjut. Pertama, penelitian tentang makna interpersonal belum menggunakan film anak berseri sebagai objek data, sedangkan film seri anak justru lebih sering ditonton dan anak membutuhkan kualitas terjemahan yang baik dalam subtitling maupun dubbing. Selain itu, peneliti memiliki kesempatan untuk mengkaji dubbing dengan menggunakan pendekatan grammar.

Dari gap penelitian di atas, peneliti mengambil salah satu film anak berseri "Thomas and Friends" untuk memperoleh data penelitian serta berfokus pada seri "Blue Mountain Mystery" yang disajikan dalam bentuk DVD. Pada versi DVD Thomas and Friends disajikan terjemahan dalam bentuk subtitling bahasa Inggris dan bahasa Indonesia serta dalam bentuk dubbing bahasa Indonesia. Berdasarkan latar belakang tersebut, peneliti akan meneliti terjemahan film "Blue Mountain Mystery" yang berbentuk dubbing dengan pendekatan Linguistik Sistemik Fungsional (LSF) melalui metafungsi Interpersonal. Data yang digunakan ialah klausa yang bermakna interpersonal-transaksional: proposal yang terdapat pada dialog tokoh dalam cerita. Maka, peneliti mengambil judul "Analisis Terjemahan Makna Interpersonal dalam Dubbing Film Thomas and Friends : Blue Mountain Mystery".

Berdasarkan kesenjangan dalam latar belakang di atas, tujuan umum penelitian ini adalah untuk mengkaji dubbing yang digunakan dalam Film Thomas and Friends : Blue Mountain Mystery. Tujuan khusus penelitian ini adalah:

1. menganalisis kualitas terjemahan dalam dubbing interpersonal-transaksional: proposal pada film Thomas and Friends : Blue Mountain Mystery,

2. menganalisis pengaruh teknik penerjemahan terhadap kualitas terjemahan dubbing interpersonal-transaksional: proposal film Thomas and Friends: Blue Mountain Mystery,

3. menganalisis dampak dubbing pada klausa interpersonal-transaksional: proposal pada film Thomas and Friends: Blue Mountain Mystery bagi anak sebagai target penonton.

Berdasarkan tujuan penelitian tersebut, penelitian ini akan fokus terhadap dubbing yang digunakan dalam film Thomas and Friends : Blue Mountain Mystery. Selanjutnya, pertanyaan penelitian ini diformulasikan sebagai berikut.

1. Bagaimana kualitas terjemahan dubbing interpersonal-transaksional: proposal film Thomas and Friends : Blue Mountain Mystery?

2. Bagaimana pengaruh teknik penerjemahan terhadap kualitas terjemahan dubbing interpersonal-transaksional: proposal? 
LINGUA, Vol. 15, No. 1, Maret 2018

p ISSN: 1979 9411; e ISSN: 2442 238X

Http://lingua.pusatbahasa.or.id; Email: presslingua@gmail.com

Center of Language and Culture Studies, Surakarta, Indonesia

Anggororeni, Pramesty; Santosa, Riyadi \& Wiratno, Tri. 2018. Analisis Terjemahan Makna Interpersonal dalam Dubbing Film Thomas and Friend: Blue Mountain Mistery. Lingua (2018), 15(1): 7 18. DOI: 10.30957/lingua.v15i.426.

3. Bagaimana dampak dubbing pada klausa interpersonal-transaksional: proposal film Thomas and Friends: Blue Mountain Mystery bagi anak sebagai target penonton?

\section{METODE}

Penelitian ini merupakan penelitian kualitatif dan bersifat deskriptif, yaitu menggambarkan kualitas terjemahan, menganalisis pengaruh teknik penerjemahan dan menganalisis dampak dubbing klausa interpersonal-trasaksional:proposal bagi anak sebagai penonton target. Penelitian ini merupakan penelitian studi kasus karena fokus pada kasus tertentu. Selain itu, penelitian ini merupakan penelitian etnografi karena peneliti turun langsung ke kelompok orang yang menjadi informan dan rater dalam penelitian. Pendekatan yang digunakan adalah pendekatan Linguistik Sistemik Fungsional (LSF).

Lokasi penelitian ini, berdasarkan definisi lokasi Lincoln dan Guba dalam Santosa (2012), ialah kelompok lokomotif di pulau Sodor dengan aktivitas di sekitar pulau Sodor dan Gunung Biru dalam DVD film Thomas and Friends: Blue Mountain Mystery. Sumber data penelitian ini ialah dokumen dan informan. Data primer yang dianalisis berupa tuturan interpersonal-transaksional dengan makna proposal, sedangkan data sekunder diperoleh dari penelitian sebelumnya yang memiliki kaitan. Sampling data penelitian ini berdasarkan kriteria yang mengacu pada tujun penelitian sehingga disebut purposive sampling.

Merujuk pada sumber data dan cara data diperoleh pada penelitian ini, maka untuk mengetahui validitas, peneliti menggunakan triangulasi sumber data dan triangulasi metode. Teknik pengumpulan data menggunakan beberapa teknik, yaitu teknik analisis dokumen, kuesioner atau angket, dan wawancara (interview). Untuk menganalisis dokumen, peneliti menggunakan analisis isi menurut Spradley, diawali dengan analisis domain, kemudian taksonomi, dan analisis komponensial yang kemudian digunakan untuk menemukan tema budaya.

\section{HASIL DAN BAHASAN}

Data yang bermakna interpersonal-transaksional:proposal ditemukan sebanyak 247 data yang terdiri dari tiga jenis klausa, yaitu klausa deklaratif (153 data), interogatif (11 data) dan imperatif (83 data). Klausa-klausa tersebut telah digolongkan dalam struktur orientation, complication, dan resolution. Pergeseran ditemukan pada 28 klausa data, yaitu 14 data klausa deklaratif dan 14 data klausa imperatif, sedangkan tidak ditemukan pergeseran pada klausa interogatif. Pergeseran yang terjadi berupa: (1) pergeseran jenis klausa; (2) pergeseran makna proposal atau fungsi sosial; dan (3) pergeseran jenis klausa dan makna atau pun fungsi sosial.

Disamping pergeseran yang terjadi, terdapat golongan jenis klausa yang mendominasi atau sering muncul pada dubbing film Thomas and Friends: Blue Mountain Mystery. Dominasi jenis klausa tersebut tampak pada diagram lingkaran 1.

Diagram lingkaran 1 menunjukkan bahwa klausa deklaratif yang paling mendominasi pada data yang jumlahnya mencapai 153 klausa $(61,94 \%)$. Sedangkan 
klausa interogatif paling jarang digunakan. Setiap jenis klausa dibagi dalam tiga domain yaitu struktur orientation, complication, dan resolution. Dari hasil penelitian diketahui bahwa klausa deklaratif paling sering digunakan pada struktur orientation. Klausa interogatif paling sering digunakan pada struktur complication. Klausa yang paling jarang digunakan ialah klausa interogatif.

Setiap klausa mengemban tugas untuk menyampaikan fungsi sosial dalam komunikasi. Pada penelitian ini ditemukan terdapat 9 data yang mengalami pergeseran makna yang awalnya bermakna proposal namun setelah diterjemahkan maknanya bergeser menjadi ellipsis. Selain itu juga terdapat klausa yang mengalami pergeseran fungsi sosial, serta data yang mengalami pergeseran jenis klausa sekaligus pergeseran makna atau fungsi sosial.

Teknik penerjemahan yang digunakan ialah varian teknik penerjemahan tunggal dan kuplet. Data dengan varian teknik penerjemahan tunggal berjumlah 214 data (86,64\%) dengan uraian 92 data pada struktur orientation, 111 data pada struktur complication, dan 11 data pada struktur resolution. Teknik penerjemahan yang digunakan ialah literal, kompresi linguistik, amplifikasi, kesepadanan lazim, modulasi, kompensasi, amplifikasi linguistik, transposisi, variasi, penghilangan, reduksi, dan

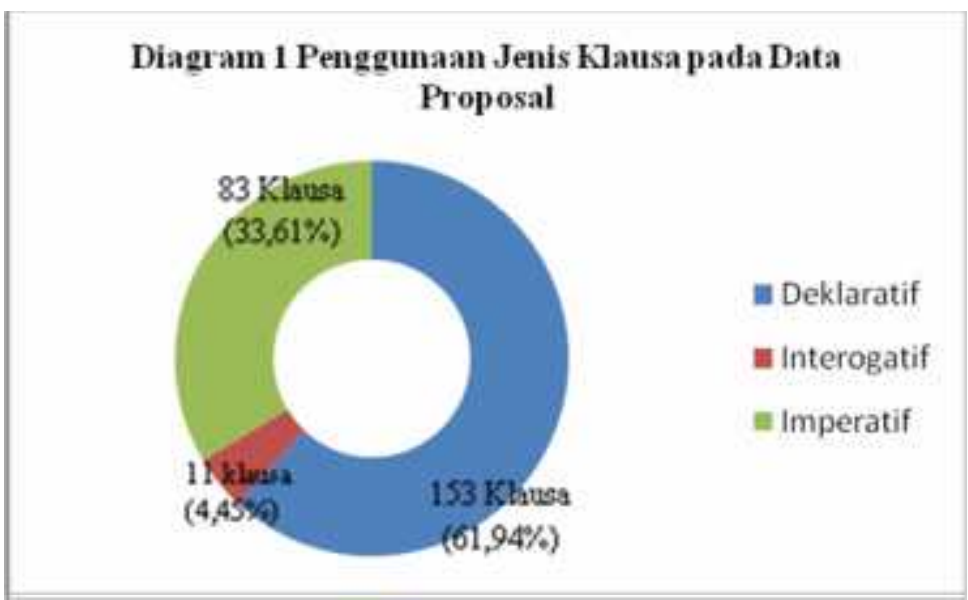
generalisasi. Data dengan varian teknik penerjemahan kuplet ditemukan sejumlah 33 data $(13,36 \%)$ yang terdiri dari 19 data pada struktur orientation, 12 data pada struktur complication, dan 2 data pada resolution. Teknik penerjemahan yang digunakan ialah literalkompensasi, literal amplifikasi, literal-reduksi, literal-modulasi, literaltransposisi, literal-kesepadanan lazim, modulasi-kesepadanan lazim, reduksi-transposisi, modulasi-transposisi, amplifikasi-reduksi, amplifikasi-kompresi linguistik.

Tabel 2 menunjukkan gambaran distribusi kualitas terjemahan setiap aspek menurut struktur teks.

Tabel 2 Distribusi Kualitas Terjemahan menurut Domain

\begin{tabular}{|l|c|c|c|c|c|c|c|c|c|}
\hline \multirow{3}{*}{ Domain } & \multicolumn{9}{|c|}{ Kualitas Terjemahan } \\
\cline { 2 - 12 } & A & KA & TA & B & KB & TB & KT & KS & KR \\
\hline Orientation & 101 & 10 & 0 & 105 & 6 & 0 & 86 & 11 & 14 \\
\hline Complication & 116 & 6 & 1 & 117 & 5 & 1 & 96 & 8 & 19 \\
\hline Resolution & 12 & 1 & 0 & 11 & 2 & 0 & 9 & 2 & 2 \\
\hline JUMLAH & $\mathbf{2 2 9}$ & $\mathbf{1 7}$ & $\mathbf{1}$ & $\mathbf{2 3 3}$ & $\mathbf{1 3}$ & $\mathbf{1}$ & $\mathbf{1 9 1}$ & $\mathbf{2 1}$ & $\mathbf{3 5}$ \\
\hline
\end{tabular}


Kualitas terjemahn dinilai dengan menggunakan indikator penilaian kualitas terjemahan menurut Nababan dkk (2012). Aspek yang dinilai meliputi keakuratan, keberterimaan, dan keterbacaan. Aspek keakuratan dinilai oleh 3 rater, aspek keberterimaan dinilai oleh 3 rater, dan aspek keterbacaan dinilai oleh 5 informan anak dengan kriteria usia 7-11 tahun.

Tabel 2 menunjukkan data hasil penilaian kualitas terjemahan dari teks. Aspek keakuratan terjemahan dengan 229 data akurat, 17 data kurang akurat dan 1 data tidak akurat. Menurut aspek keberterimaan, terjemahan yang berterima merupakan yang paling dominan yaitu sebanyak 233 data. Data tersebut terdiri dari 105 data pada orientation, 117 data pada complication dan 11 data pada resolution. Pada aspek keterbacaan, terjemahan dengan tingkat keterbacaan tinggi berjumlah 191 data, terdiri dari 86 pada orientation, 96 pada complication, dan 9 pada resolution. Dilihat berdasarkan jenis klausanya, kualitas terjemahan klausa deklaratif dinilai akurat, berterima dan memiliki tingkat keterbacaan tinggi. Hal yang sama terjadi pada terjemahan klausa interogatif dan klausa imperatif.

Berdasarkan hasil temuan tersebut, peneliti menjelaskan hubungan speech function (Halliday, 2004:108) terhadap jenis klausa dan kualitas terjemahan dengan melihat struktur teks. Merujuk pada teori LSF tentang klausa, makna setiap klausa memiliki fungsi-fungsi (speech function) yang berkaitan dengan struktur gramatikal dalam berbagai bentuk. Halliday (2004:108) menjelaskan bahwa speech function dibagi menjadi giving and demanding goods and services (proposal) dan giving and demanding information (proposisi).

Data penelitian yang diambil dengan menggunakan teori Haliday ini kemudian dihubungkan dengan kualitas terjemahan dengan memperhatikan struktur teks dalam poin-poin berikut.

\section{Pengaruh teknik penerjemahan terhadap kualitas terjemahan proposal menurut struktur teks film}

Dalam makna interpersonal, realisasi interaksi sosial dapat diwujudkan dalam sistem MOOD yang di dalamnya terealisasi jeni-jenis MOOD atau klausa, yaitu indikatif (deklaratif dan interogatif) dan imperatif. Berikut penggunaan jenis klausa pada teks dubbing film.

Tabel 3 Perbandingan Jenis Klausa pada Proposal

\begin{tabular}{|c|c|c|c|c|}
\hline \multirow[t]{2}{*}{ Proposal } & \multirow{2}{*}{$\begin{array}{c}\text { Jenis klausa } \\
\text { berdasarkan teori }\end{array}$} & \multicolumn{3}{|c|}{ Jenis klausa berdasarkan hasil penelitian } \\
\hline & & Orientation & Complication & Resolution \\
\hline $\begin{array}{l}\text { Giving } \\
\text { goods and } \\
\text { services } \\
\text { (Memberi) }\end{array}$ & $\begin{array}{l}\text { Variasi } \\
\text { - Deklaratif } \\
\text { - Interogatif } \\
\text { - Imperatif }\end{array}$ & $\begin{array}{l}\text { Variasi } \\
\text { - Deklaratif } \\
\text { - Interogatif } \\
\text { - Imperatif }\end{array}$ & $\begin{array}{l}\text { Variasi } \\
\text { - Deklaratif } \\
\text { - Interogatif } \\
\text { - Imperatif }\end{array}$ & Deklaratif \\
\hline $\begin{array}{l}\text { Demanding } \\
\text { goods and }\end{array}$ & Imperatif & $\begin{array}{l}\text { Variasi } \\
\text { - Deklaratif }\end{array}$ & $\begin{array}{l}\text { Variasi } \\
\text { - Deklaratif }\end{array}$ & - Deklaratif \\
\hline
\end{tabular}


Http://lingua.pusatbahasa.or.id; Email: presslingua@gmail.com Center of Language and Culture Studies, Surakarta, Indonesia

Anggororeni, Pramesty; Santosa, Riyadi \& Wiratno, Tri. 2018. Analisis Terjemahan Makna Interpersonal dalam Dubbing Film Thomas and Friend: Blue Mountain Mistery. Lingua (2018), 15(1): 7 18. DOI: 10.30957/lingua.v15i.426.

\begin{tabular}{|l|l|l|l|l|}
\hline $\begin{array}{l}\text { services } \\
\text { (Meminta) }\end{array}$ & - Interogatif & - Interogatif & - Interogatif \\
\hline
\end{tabular}

Menurut teori, klausa yang bermakna proposal-memberi (giving goods and services) biasanya diungkapkan dengan bentuk klausa yang bervariasi. Sedangkan berdasarkan hasil penelitian dubbing film, terjadi kongruensi jenis klausa karena juga diungkapkan dengan klausa yang bervariasi. Klausa yang mengemban makna proposalmeminta (demanding goods and services) biasanya diungkapkan dalam bentuk klausa imperatif namun pada hasil penelitian menunjukkan klausa yang bervariasi dapat mengemban makna proposal-meminta, khususnya klausa imperatif. Hal ini menunjukkan kongruensi teori dengan hasil penelitian. Dengan demikian, pada teks film, jenis klausa apapun tetap memiliki kemungkinan untuk mengemban makna proposal, baik proposal-memberi maupun proposal-meminta.

Selain jenis klausa, peneliti juga menyimpulkan fungsi sosial yang diemban oleh klausa berdasarkan makna proposalnya. (Tabel 4).

Tabel 4 Perbandingan Fungsi Sosial pada Proposal

\begin{tabular}{|c|c|c|c|c|}
\hline \multirow[t]{2}{*}{ Proposal } & \multirow{2}{*}{$\begin{array}{c}\text { Fungsi Sosial } \\
\text { berdasarkan teori }\end{array}$} & \multicolumn{3}{|c|}{ Jenis klausa berdasarkan hasil penelitian } \\
\hline & & Orientation & Complication & Resolution \\
\hline $\begin{array}{l}\text { Giving } \\
\text { goods and } \\
\text { services } \\
\text { (Memberi) }\end{array}$ & $\begin{array}{l}\text { Offering } \\
\text { (penawaran) }\end{array}$ & $\neq$ Offering & $\neq$ Offering & $\neq$ Offering \\
\hline $\begin{array}{l}\text { Demanding } \\
\text { goods and } \\
\text { services } \\
\text { (Meminta) }\end{array}$ & $\begin{array}{l}\text { Command } \\
\text { (memerintah) }\end{array}$ & $\begin{array}{l}\text { Command } \\
\text { dan fungsi } \\
\text { sosial lain }\end{array}$ & $\begin{array}{l}\text { Command } \\
\text { dan fungsi } \\
\text { sosial lain }\end{array}$ & $\neq$ command \\
\hline
\end{tabular}

Klausa bermakna proposal-memberi biasanya mengemban fungsi sosial penawaran, sedangkan berdasarkan hasil penelitian, fungsi sosial yang muncul sangat bervariasi. Klausa bermakna proposal-memintabiasanya mengemban fungsi sosial memerintah dan hasil penelitian menunjukkan kongruensi tersebut namun variasi fungsi sosial tetap ada. Maka dilihat dari sudut pandang fungsi sosial dan jenis klausa, maka klausa bermakna proposal-memberi pada suatu teks film dapat mengemban fungsi sosial yang beranekaragam dan diungkapkan dengan klausa yang bervariasi. Begitu juga dengan klausa yang bermakna proposal-meminta pada teks film dapat pula mengemban fungsi sosial yang bervariasi dan jenis klausa yang juga bervariasi.

\section{Dampak kualitas terjemahan bagi anak sebagai penonton target}

Anak-anak usia 7-11 tahun merupakan penonton target pada penelitian ini. Dampak kualitas terjemahan bagi anak sebagai penonton target dapat dilihat dari aspek keterbacaan terjemahan. Nababan dkk (2012:49) menjelaskan bahwa tingkat keterbacaan terjemahan merujuk pada derajat kemudahan suatu teks terjemahan untuk dipahami pembaca sasaran. Untuk mengetahui penghambat pemahaman penonton 
targget, peneliti menglasifikasikan faktor-faktor penyebab terhambatnya pemahaman penonton dan merancang indikator penghambat sebagai tolok ukur menilai dampak kualitas terjemahan bagi penonton target. Adapun indikator yang digunakan ialah latar belakang pengetahuan penonton (LBP penonton), panjang klausa, dan diksi. Indikator penghambat ditemukan pada terjemahan makna proposal yang memiliki tingkat keterbacaan sedang dan rendah. Dampak kualitas terjemahan bagi anak sebagai penonton target tampak pada tabel 5 .

Tabel 5 Pemahaman Penonton berdasarkan Struktur Teks dan Jenis Klausa

\begin{tabular}{|c|c|c|c|c|}
\hline \multirow[t]{2}{*}{ Struktur Teks } & \multirow{2}{*}{$\begin{array}{c}\text { Perbandingan } \\
\text { proposal dan tingkat } \\
\text { keterbacaan }\end{array}$} & \multicolumn{3}{|c|}{ Pemahaman Penonton menurut Klausa } \\
\hline & & Deklaratif & Interogatif & Imperatif \\
\hline \multirow[t]{3}{*}{ Orientation } & Menurut fungsi sosial & $\begin{array}{l}\text { p.memberi lebih } \\
\text { sulit dari } \\
\text { p.meminta }\end{array}$ & $\begin{array}{c}\text { p.memberi dan } \\
\text { p.meminta } \\
\text { mudah dipahami }\end{array}$ & $\begin{array}{l}\text { p.memberi lebih } \\
\text { mudah dari } \\
\text { p.meminta }\end{array}$ \\
\hline & $\begin{array}{l}\text { Menurut tingkat } \\
\text { keterbacaan }\end{array}$ & $\begin{array}{c}\text { p.memberi lebih } \\
\text { sulit dari } \\
\text { p.meminta }\end{array}$ & $\begin{array}{c}\text { p.memberi dan } \\
\text { p.meminta } \\
\text { mudah dipahami }\end{array}$ & $\begin{array}{c}\text { p.memberi lebih } \\
\text { sulit dari } \\
\text { p.meminta }\end{array}$ \\
\hline & Simpulan & kongruen & Kongruen & Tdk kongruen \\
\hline \multirow[t]{3}{*}{ Complication } & Menurut fungsi sosial & $\begin{array}{c}\text { p.memberi lebih } \\
\text { sulit dari } \\
\text { p.meminta }\end{array}$ & $\begin{array}{l}\text { p.memberi lebih } \\
\text { mudah dari } \\
\text { p.meminta }\end{array}$ & $\begin{array}{c}\text { p.memberi lebih } \\
\text { mudah dari } \\
\text { p.meminta }\end{array}$ \\
\hline & $\begin{array}{l}\text { Menurut tingkat } \\
\text { keterbacaan }\end{array}$ & $\begin{array}{l}\text { p.memberi lebih } \\
\text { sulit dari } \\
\text { p.meminta }\end{array}$ & $\begin{array}{c}\text { p.memberi lebih } \\
\text { mudah dari } \\
\text { p.meminta }\end{array}$ & $\begin{array}{l}\text { p.memberi lebih } \\
\text { mudah dari } \\
\text { p.meminta }\end{array}$ \\
\hline & Simpulan & kongruen & Kongruen & kongruen \\
\hline \multirow[t]{3}{*}{ Resolution } & Menurut fungsi sosial & $\begin{array}{l}\text { p.memberi lebih } \\
\text { sulit dari } \\
\text { p.meminta }\end{array}$ & $\begin{array}{c}\text { p.meminta } \\
\text { mudah dipahami }\end{array}$ & - \\
\hline & $\begin{array}{l}\text { Menurut tingkat } \\
\text { keterbacaan }\end{array}$ & $\begin{array}{l}\text { p.memberi lebih } \\
\text { mudah dari } \\
\text { p.meminta }\end{array}$ & $\begin{array}{c}\text { p.meminta } \\
\text { mudah dipahami }\end{array}$ & - \\
\hline & Simpulan & Tdk kongruen & Kongruen & - \\
\hline
\end{tabular}

Dapat disimpulkan bahwa klausa deklaratif proposal-memberi lebih sulit dipahami oleh penonton target, baik pada struktur orientation, complication, maupun resolution. Klausa interogatif pada struktur orientation merupakan yang paling mudah dipahami penonton. Pada struktur complication, klausa interogatif proposal-memberi lebih mudah dipahami dari pada proposal-meminta. Struktur resolution hanya terdiri dari klausa interogatif proposal-meminta yang juga mudah dipahami oleh penonton. Disamping itu, klausa imperatif proposal-memberi juga lebih mudah dipahami penonton dibandingkan dengan klausa imperatif proposal-meminta.

Dengan demikian, dapat disimpulkan bahwa terjemahan proposal teks dubbing film mudah dipahami oleh penonton target jika diksinya tepat dan sesuai dengan latar 
belakang pengetahuan penonton target (terutama pada istilah-istilah teknis), serta tidak banyak menggunakan klausa yang panjang dan komplek.

\section{SIMPULAN}

Berdasarkan hasil temuan dan pembahasan, dapat disimpulkan sebagai berikut.

1. Penilaian kualitas terjemahan secara menyeluruh dilihat dari aspek keakuratan, keberterimaan, dan keterbacaan menunjukkan bahwa terjemahan teks dubbing film Thomas and Friends: Blue Mountain Mystery tergolong akurat, berterima dan memiliki tingkat keterbacaan yang tinggi. Hal ini berarti makna dan pesan film dapat tersampaikan dengan baik kepada penonton target yang masih berusia 7-11 tahun.

2. Klausa yang bermakna proposal-memberi pada suatu teks film dapat mengemban fungsi sosial yang beranekaragam dan diungkapkan dengan klausa yang bervariasi. Begitu juga dengan klausa yang bermakna proposal-meminta pada teks film dapat pula mengemban fungsi sosial yang beragam dan jenis klausa yang juga bervariasi.

3. Terjemahan klausa bermakna proposal pada teks dubbing film Thomas and Friends: Blue Mountain Mystery mudah dipahami oleh penonton target jika diksinya tepat dan sesuai dengan latar belakang pengetahuan penonton target (terutama pada istilah-istilah teknis), serta tidak banyak menggunakan klausa yang panjang dan komplek.

\section{DAFTAR PUSTAKA}

Barnstone, Will. (1993). The Poetics of Translation. London: Yale University Press.

Bernschutz, Maria, Ph.D. (2010). Empirical Study of Subtitled Movie. Translation Journal.

Blinn, Miika. (2008). The Dubbing Standard: Its History and Efficiency Implications for Film Distributors in the German Film Market. London: Freie University Berlin.

Burczynska, Paulina. (2012). Translation of Cultural Items in Dubbed Animated Comedies. Translation Journal.

Denzin, Norman K, Yvonna S. Lincoln. (2009) handook of Qualitatif research. Yogyakarta: Pustaka Pelajar.

Fostios, Karamitoglou. (1998). A proposed set of Subtitling Standards in Europe. Translation Journal.

Halliday, M.A.K. \& Mattheson, Christian M.I.M. (2004). An Introduction Functional Grammar. New York: Oxford University Press.

Hapsari, Reni. (2012). An Analysis on the Type of Translation Shifts as Translation Teqniques and Qualities in Two Selected Children Bilingual Books: A Sistemic Functional Perspective. Surakarta: UNS.

Jankowska, Anna. (2010). Translating Humor in Dubbing and Subtitling. Krakow: Jagiellonian University Poland.

Kridalaksana, Harimurti. (1993). Kamus Linguistik. Jakarta: Gramedia Pustaka Utama. 
McCabe \& Heilman. (2007). Textual and Interpersonal Differences between a News Report and an Editorial. Madrid.

Nababan dkk. (2012). Pengembangan Model Penilaian Kualitas Terjemahan. Surakarta: UNS.

Nisaa', Rohmita Khoirun. (2011). Analisis Teknik, Metode, dan Ideologi Penerjemahan Subtitle Film Beckham Unwrapped dan Dampaknya pada Kualitas Terjemahan. Surakarta: UNS.

Nurgiyantoro, Burhan. (2005). Tahapan Perkembangan Anak dan Pemilihan Bacaan Sastra Anak. Yogyakarta: FBS-UNY.

Pengsun \& Fengfeng. (2013). A Contrastive Study of Political Speeches in Presidential Election of Interpersonal Meaning. Canada.

Pettit, Zoe. (2005). Translating Register, Style and Tone in Dubbing and Subtitling. Journal: University of Greenwich.

Purbasari, Prima. (2011). Analisis Teknik, Metode, dan Ideologi Penerjemahan dalam Subtitle Film "Jane Eyre" Versi Serial TV BBC. Surakarta: UNS.

Santosa, Riyadi. (2012). Metode Penelitian Kualitatif Kebahasaan. Surakarta: UNS.

Sitoresmi, Ulupi. (2012). Kajian Terjemahan 'Mother Goose Rhymes' dalam Film Barney Episode 'Rhyme Time and Rhytm'. Surakarta: UNS.

Swarkowska, Agnieszka. (2005). The Power of Film Translation. Translation Journal.

Tveit, Jan Emil. (2009). Dubbing versus Subtitling: Old Battle - Ground Revisited. Journal.

Weibel, David \& Groner, Rudolf. (2009). Dubbing or Subtitling? Effects on Spatial Presence, Transportation, Flow and Enjoyment. Hogrefe Publising.

Widiani, Agustin. (2012). Analisis Teknik, Metode, dan Ideologi Penerjemahan Subtitle Film “Leapyear" Versi Non-Komersial dan Versi VCD Resmi dan Dampaknya pada Kualitas Terjemahan. Surakarta: UNS.

Wiratno \& Santosa. (2013). Pengantar Linguistik Umum, Cetakan kedua. Jakarta: Universitas Terbuka. 
LINGUA, Vol. 15, No. 1, Maret 2018

p ISSN: 1979 9411; e ISSN: 2442 238X

Http://lingua.pusatbahasa.or.id; Email:presslingua@gmail.com

Center of Language and Culture Studies, Surakarta, Indonesia

Anggororeni, Pramesty; Santosa, Riyadi \& Wiratno, Tri. 2018. Analisis Terjemahan Makna Interpersonal dalam Dubbing Film Thomas and Friend: Blue Mountain Mistery.

Lingua (2018), 15(1): 7 18. DOI: 10.30957/lingua.v15i.426. 